CLINICAL STUDY

\title{
GH deficiency in patients irradiated for acromegaly: significance of GH stimulatory tests in relation to the $24 \mathrm{~h}$ GH secretion
}

\author{
A A van der Klaauw ${ }^{1}$, A M Pereira ${ }^{1}, \mathrm{~S}$ W van Thiel ${ }^{1}$, J W A Smit ${ }^{1}$, E P M Corssmit ${ }^{1}$, N R Biermasz ${ }^{1}$, M Frolich ${ }^{2}$, \\ A Iranmanesh ${ }^{3}$, J D Veldhuis ${ }^{4}$, F Roelfsema ${ }^{1}$ and J A Romijn ${ }^{1}$ \\ Departments of ${ }^{1}$ Endocrinology and Metabolism, C4-R, and ${ }^{2}$ Clinical Chemistry, Leiden University Medical Center, PO Box 9600,2300 RC Leiden, The \\ Netherlands, ${ }^{3}$ Endocrine Service, Research and Development, Salem Veterans Affairs Medical Center, Salem, Virginia 24153, USA and ${ }^{4}$ Endocrine Research \\ Unit, Department of Internal Medicine, Mayo School of Graduate Medical Education, General Clinical Research Center, Mayo Clinic, Rochester, Minnesota \\ 55905, USA \\ (Correspondence should be addressed to F Roelfsema; Email: f.roelfsema@lumc.nl)
}

\begin{abstract}
Background: Radiotherapy for pituitary adenomas frequently leads to GH deficiency (GHD). The characteristics of GH secretion in GHD induced by postoperative radiotherapy for acromegaly are not known.

Hypothesis: In the long term, stimulated and spontaneous GH release is not different between patients with GHD treated by postoperative radiotherapy for acromegaly or for other pituitary adenomas.

Design/subjects: We compared the characteristics of basal and stimulated GH secretion in patients with GHD, who had previously received adjunct radiotherapy after surgery for GH-producing adenomas $(n=10)$ vs for other pituitary adenomas $(n=10)$. All patients had a maximal GH concentration by insulin tolerance test (ITT) of $3 \mu \mathrm{g} / \mathrm{l}$ or less, compatible with severe GHD. Mean time after radiation was 17 and 18.7 years, respectively. Stimulated GH release was also evaluated by infusion of growth hormone-releasing hormone (GHRH), GHRH-arginine and arginine, and spontaneous GH by $10 \mathrm{~min}$ blood sampling for $24 \mathrm{~h}$. Pulse analyses were performed by Cluster and approximate entropy. Outcomes: There were no differences between both patient groups in stimulated GH concentrations in any test. Spontaneous GH secretion was not different between both patient groups, including basal GH release, pulsatility and regularity. Pulsatile secretion was lost in two acromegalic and three nonacromegalic patients. Insulin-like growth factor-I (IGF-I) was below -2 s.D. score in nine patients in each group.

Conclusion: Acromegalic patients treated by surgery and postoperative radiotherapy with an impaired response to the ITT do not differ, in the long term, in GH secretory characteristics from patients treated similarly for other pituitary tumors with an impaired response to the ITT. The ITT (or the GHRHarginine test) is therefore reliable in establishing the diagnosis of GHD in patients treated for acromegaly by surgery and radiotherapy.
\end{abstract}

European Journal of Endocrinology 154 851-858

\section{Introduction}

The aim of treatment in acromegaly is first to relieve the symptoms of growth hormone $(\mathrm{GH})$ excess and the mass effects of the pituitary tumor. Additional aims are restoration of the metabolic changes and a reduction in the increased risk of mortality associated with active acromegaly (1). Ideally, the therapy should be directed towards the restoration of physiological GH secretion, which is achieved when responses to dynamic stimuli and $24 \mathrm{~h} \mathrm{GH}$ production are normalized, including restoration of secretory characteristics such as diurnal rhythm and secretory regularity. At the present time only surgery is capable of fulfilling these goals in a limited number of patients, even by expert surgery $(2-5)$. Therefore, frequent additional treatment is required, which may be given in the form of pharmacotherapy (e.g. somatostatin analogs, GHreceptor blockade drugs, dopaminergic drugs or combinations thereof) or as radiotherapy.

After pituitary irradiation a decline of $\sim 50 \%$ in serum GH levels is observed in the first 2 years and of $\sim 75 \%$ after 5 years $(6-8)$. The normalization of $\mathrm{GH}$ and insulin-like growth factor-I (IGF-I) levels during followup after radiotherapy is dependent mainly on the preirradiation serum GH concentrations. Many patients with other pituitary adenomas (e.g. non-functioning adenomas, adrenocorticotropic hormone (ACTH)- or prolactin (PRL)-secreting adenomas) develop GH deficiency (GHD) after pituitary irradiation (9). Therefore, it seems logical to expect long-term GHD in acromegaly after such treatment. In accordance with this expectation, we have documented a decreased response of GH to insulin-induced hypoglycemia in 36\% 
of patients with acromegaly, during long-term follow-up of postoperative radiotherapy (7).

In acromegalic patients with GHD after radiotherapy, little information is available on spontaneous $24 \mathrm{~h} \mathrm{GH}$ secretion and other GH-stimulation tests in relation to the insulin tolerance test (ITT), the most widely used and recommended GH-stimulating measure for the diagnosis of GHD (10). Therefore, we specifically wished to address whether basal and stimulated GH secretion differed between those patients with GHD who had previously received adjunct radiotherapy after surgery for GH-producing adenomas $(n=10)$ and those who had received adjunct radiotherapy for other pituitary adenomas $(n=10)$. In both groups, GHD was defined as a maximal GH concentration of $3 \mu \mathrm{g} / \mathrm{l}$ during the ITT, compatible with severe GHD. We therefore explored various aspects of $\mathrm{GH}$ pathophysiology, including spontaneous $24 \mathrm{~h} \mathrm{GH}$ secretion, GH-stimulating tests aimed at the pituitary gland or acting indirectly, prevailing IGF-I concentrations and the mutual interrelations between these parameters.

\section{Methods}

\section{Patients}

Ten previously operated and irradiated patients with a GH-secreting macroadenoma and 10 identically treated patients with a non-functioning pituitary macroadenoma $(n=8)$ or an ACTH-producing microadenoma $(n=2)$, matched for gender and age, were enrolled (pituitary adenoma control group: PT controls). The acromegalic patients were chosen from a cohort of clinically inactive acromegalic patients, previously ( $>10$ years) treated by transsphenoidal surgery and because of persisting postoperative $\mathrm{GH}$ excess by postoperatively conventional radiotherapy (40-45 Gy). This cohort of acromegalic patients has previously been described extensively (7). The inclusion criterion was a subnormal GH response to the ITT (short-acting insulin $0.05-0.1 \mathrm{U} / \mathrm{kg}$ body weight, blood samples drawn at 0 , 20, 30, 45, 60 and $90 \mathrm{~min}$; glucose levels were required to drop below $2.2 \mathrm{mmol} / \mathrm{l}$ ). The increase in $\mathrm{GH}$ concentrations was considered insufficient when peak $\mathrm{GH}$ response was below $3 \mu \mathrm{g} / \mathrm{l}(10)$. The number of pituitary deficiencies other than that of GH were similar for both groups $(P=0.25)$. Three deficient anterior pituitary functions were established in six acromegalic patients and in seven of the control patient group. Replacement treatment for secondary hypocortisolism was given to seven acromegaly patients and to nine control patients (NS), thyroid hormone therapy was given to seven and eight patients, respectively (NS), and treatment for secondary hypogonadism to four patients of each group (NS). Three of the ten acromegalic patients and four of the ten control patients used lipidlowering drugs. None of the patients used dopamine agonists, but two of the patients in the PT control group used inhalation $\beta_{2}$-sympathicomimetics and two of the patients in the acromegalic group used $\beta$-adrenoreceptor blocking medication. The purpose, nature and possible risks of the study were explained to all subjects and written informed consent was obtained. The study protocol was approved by the ethics committee of the Leiden University Medical Center.

\section{Clinical protocol}

First, the GH secretory reserve was assessed by three stimulation tests in addition to the ITT, and subsequently spontaneous GH secretion was measured over a period of $24 \mathrm{~h}$ with blood sampling intervals of $10 \mathrm{~min}$

The GH stimulation tests were carried out in random order on separate days (during a 2 week period) in the fasting condition. The following tests were performed: the growth hormone-releasing hormone (GHRH) test (Ferring, Hoofddorp, The Netherlands: $1 \mu \mathrm{g} / \mathrm{kg}$ body weight by i.v. bolus injection, with blood samples drawn at $0,20,30,45,60$ and $90 \mathrm{~min}$ ), the L-arginine infusion test $(500 \mathrm{mg} / \mathrm{kg}$ body weight with a maximum of $30 \mathrm{~g}$, infusion over $30 \mathrm{~min}$, with blood samples drawn at $0,30,45,60,90$ and $120 \mathrm{~min}$ ), and the combined GHRH-arginine test as an i.v. bolus injection of GHRH ( $1 \mu \mathrm{g} / \mathrm{kg}$ body weight) after which L-arginine ( $500 \mathrm{mg} / \mathrm{kg}$ body weight with a maximum of $30 \mathrm{~g}$ ) was infused over $30 \mathrm{~min}$, with blood samples drawn at 0 , 30, 45, 60, 90 and $120 \mathrm{~min}$. The peak serum response of $\mathrm{GH}$ was used as the primary variable for analysis of the stimulation tests.

For the $24 \mathrm{~h}$ sampling study, the patients were admitted to the Clinical Research Center in the morning. An indwelling i.v. cannula was inserted in a forearm vein at least 60 min before sampling began. Blood samples were withdrawn at 10 min intervals for $24 \mathrm{~h}$, starting at $0900 \mathrm{~h}$. A slow infusion of $0.9 \% \mathrm{NaCl}$ and heparin $(1 \mathrm{U} / \mathrm{ml})$ was used to maintain patency of the i.v. catheter. The subjects were not allowed to sleep during the daytime. Meals were served at 0900, 1230 and $1730 \mathrm{~h}$. Lights were turned off between 2200 and $2400 \mathrm{~h}$. Plasma samples for $\mathrm{GH}$ measurements were collected, centrifuged at $4{ }^{\circ} \mathrm{C}$ for $7 \mathrm{~min}$, and stored at $-20^{\circ} \mathrm{C}$ until later analysis.

\section{Assays}

GH concentrations in the samples of the stimulation tests were measured by time-resolved immunofluorometric assay (Wallac Inc., Turku, Finland). Reference values, listed in the tables and main text, were obtained with the same assay. Human biosynthetic GH (Pharmacia and Upjohn) was used as standard and calibrated against WHO-IRP 80-505; the detection limit of this GH assay is $0.01 \mu \mathrm{g} / \mathrm{l}$, with an inter-assay coefficient of variation of $1.6-8.4 \%$, between 0.1 and $15 \mu \mathrm{g} / \mathrm{l}$ 
$(1 \mu \mathrm{g} / \mathrm{l}=2.6 \mathrm{mU} / \mathrm{l}) . \mathrm{GH}$ concentrations in the serum samples of $24 \mathrm{~h}$ profiles of the patients in this study were measured with the more sensitive automatic immunochemiluminescence assay (Nichols Diagnostics Institute, San Clemente, CA), using $22 \mathrm{kDa}$ rhGH as standard. Cross reactivity with $20 \mathrm{kDa}$ GH was 30\%. Assay sensitivity (defined as 3 s.D. above the zero dose level) was $0.005 \mu \mathrm{g} / \mathrm{l}$. Median intra- and inter-assay coefficients of variation were 5.2 and $8.3 \%$, respectively. $\mathrm{GH}$ concentration was measured in every sample in duplicate. All samples from a single subject were assayed together to eliminate inter-assay variability.

Serum IGF-I concentrations were determined by Immulite 2000 (DPC, Los Angeles, CA). The assay is calibrated with WHO 2nd International Standard $87 / 518$. The sensitivity of the assay is $20 \mu \mathrm{g} / \mathrm{l}$. The intra-assay precision is $2.6-4.3 \%$ over the adult operating range. All serial samples in this study were run in the same assay.

\section{Calculations and statistics}

CIuster analysis. Cluster analysis was used for the detection of discrete GH peaks (11). This computerized pulse algorithm is largely model free, and identifies statistically significant pulses in relation to dosedependent measurement error in the hormone time series. For the present analysis a $2 \times 1$ test cluster configuration was used, two data points for the test nadir and one for the test peak, and a $t$-statistic of 2.0 for the up- and down-strokes, which minimizes both false positive and false negative peaks. The locations and widths of all significant concentration peaks were identified, the total number of peaks was counted, and the mean peak interval was calculated in minutes. In addition, the following pulse parameters were determined: peak height (highest value attained within the peak), incremental peak amplitude (the difference between peak height and pre-peak nadir), and area under the peak. Inter-pulse valleys were identified as regions embracing nadirs with no intervening upstrokes. The total area under the curve was also calculated, as well as the summed pulse areas.
Approximate entropy (ApEn). ApEn was used as a scale- and model-independent regularity statistic to quantitate the orderliness or regularity of serial $\mathrm{GH}$ serum concentrations over $24 \mathrm{~h}$. Normalized ApEn parameters of $m=1$ (test range) and $r=20 \%$ (threshold) of the intra-series s.D. were used, as described previously (12). The ApEn metric evaluates the consistency of recurrent subordinate (non-pulsatile) patterns in successive data, and thus yields information distinct from and complimentary to cosinor and deconvolution (pulse) analyses (13). Higher absolute ApEn values denote greater relative randomness of hormone patterns, e.g. as observed for ACTH in Cushing disease, GH in acromegaly, and PRL in prolactinomas (14-16). Normalized ApEn ratios of observed to 1000 randomly shuffled data series are reported.

Statistical analysis. Results are presented as the mean and 95\% confidence interval, unless stated otherwise. Statistical analyses were carried out with the Kolmogorov-Smirnov test. Comparisons between the GH stimulation tests were carried out with the general linear model (GLM), with appropriate post hoc contrasts. Associations between variables were quantified by Spearman's rho test. Statistical calculations were performed with Systat, version 11 (Systat Software Inc., Richmond, CA) or SPSS version 11 (SPSS Inc., Chicago, IL). $P<0.05$ was considered significant.

\section{Results \\ Patients (Table 1)}

The mean age $( \pm$ s.D.) of the patients treated for acromegaly was $5 \overline{6} \pm 12$ years and of the PT control group $62 \pm 12$ years $(P=0.30)$. Body mass index (BMI) of the acromegalic patients was $29.1 \pm 2.9 \mathrm{~kg} / \mathrm{m}^{2}$ and $28.3 \pm 4.5 \mathrm{~kg} / \mathrm{m}^{2}$ in the PT control group $(P=0.66)$. Conventional radiation therapy with an $8 \mathrm{MeV}$ linear accelerator, with a total tumor dose of 40-45 Gy and fractionated in at least 20 sessions, was given $17.0 \pm$ 7.0 years prior to testing in the acromegalic group, and $18.7 \pm 7.6$ years in the PT control group $(P=0.67)$.

Table 1 Clinical characteristics of the patient groups.

\begin{tabular}{lccc}
\hline & Patients treated for acromegaly & Pituitary tumor control patients & $P$-value \\
\hline Age (years) & $56(47-65)$ & $62(53-71)$ & 0.30 \\
Sex (males/females) & $4 / 6$ & $5 / 5$ & 0.65 \\
BMI $\left(\mathrm{kg} / \mathrm{m}^{2}\right)$ & $29.1(27.1-31.2)$ & $28.3(25.1-31.5)$ & 0.66 \\
IGF-I $(\mu \mathrm{g} / \mathrm{l})$ & $59(36-82)$ & $56(41-71)$ & 0.96 \\
Interval between stimulation tests and & $17.0(7-25)$ & $18.7(11-28)$ & 0.67 \\
radiotherapy (years) & & & \\
\hline
\end{tabular}

Data are shown as the mean and the $95 \%$ confidence interval. Statistical comparisons were performed with the Kolmogorov-Smirnov test. 


\section{Stimulation tests (Table 2, Fig. 1)}

The GH responses to the four stimulation tests are displayed in Fig. 1. The peak values reached during these tests are shown in Table 2. No significant differences in $\mathrm{GH}$ responses between the two groups were present for any test.

However, the figure clearly demonstrates the differences in magnitude of $\mathrm{GH}$ responses between the tests. Indeed, the univariate ANOVA of the $\mathrm{GH}$ peak values applied to the combined patient groups was highly significant $(P<0.001)$. Post hoc analyses revealed that the GH response to the ITT was not different from the arginine test $(P=0.39)$. The GH responses in the GHRH and the combined GHRHarginine tests were significantly higher than in the ITT $(P<0.001)$. The GH response to insulin correlated significantly with that to the combined GHRHarginine test $(R=0.64, \quad P=0.003)$, and arginine alone $(R=0.63, P=0.003)$, but not with the $\mathrm{GH}$ response to GHRH $(R=0.42, P=0.07)$.

The mean IGF-I concentration was $56 \mu \mathrm{g} / \mathrm{l}(95 \%$ confidence interval 41-71 $\mu \mathrm{g} / \mathrm{l})$ in control patients, and $59 \mu \mathrm{g} / \mathrm{l}(95 \%$ confidence interval $36-82 \mu \mathrm{g} / \mathrm{l})$ in acromegalic patients $(P=0.96)$. No relevant correlations were found within the limited range of IGF-I values. IGF-I was below -2 s.D. score in nine patients in each group.

\section{Twenty four hour GH profiles (Table 3, Fig. 2)}

Representative $24 \mathrm{~h}$ GH profiles of two acromegalic patients and two controls are shown in Fig. 2. The results of the Cluster analysis are listed in Table 3. It should be noted that two acromegalic patients and three PT control patients had no statistically significant GH pulses, although their GH levels were detectable. For the remaining patients no differences could be demonstrated with respect to integrated area, mean $\mathrm{GH}$ concentration, mean pulse height, mean pulse area (mass) and nadir concentration.

The integrated area, reflecting $24 \mathrm{~h}$ GH secretion, correlated with the peak GH of the combined GHRHarginine test $(R=0.78, P=0.001)$, and also with that of the ITT $(R=0.54, P=0.036)$, but not with the other two stimulation tests.

The ApEn (1,20\%) ratio was no different between acromegalic patients and PT controls (mean 0.76; 95\% confidence interval $0.70-0.81$ and 0.69 ; $95 \%$ confidence interval $0.57-0.81$, respectively, $P=0.25)$. The reference value for these patients groups is $0.41,95 \%$ confidence interval 0.36-0.45.

\section{Discussion}

In this study we compared the characteristics of $\mathrm{GH}$ secretion between GH-deficient acromegalic patients and GH-deficient patients with other pituitary adenomas after long-term follow-up of postoperative radiotherapy. We found that patients treated by transsphenoidal surgery and additional radiotherapy for acromegaly with an impaired GH response to the ITT did not differ with regard to stimulated and spontaneous GH secretion from patients treated analogously for other pituitary adenomas, who had impaired GH response to the ITT.

Hypopituitarism is a well-recognized sequel of radiotherapy for pituitary tumors, and GH secretion is usually the first hormone affected (9). The ITT is an effective test to define GHD (10), since responses reflect the functional integrity of the hypothalamicpituitary-GH axis $(17,18)$. The hypothalamus may be more vulnerable to radiation-induced damage than the pituitary gland, since the pituitary remains responsive to hypothalamic-releasing hormones after radiation (19). GHD after radiotherapy for pituitary tumors may therefore occur due to failure of synthesis and/or delivery of endogenous GHRH (or other putative GH-releasing substances, e.g. hypothalamic ghrelin) to the pituitary $(20,21)$. One could hypothesize that the function of the hypothalamicpituitary-GH axis in acromegalic patients treated by postoperative radiotherapy, as assessed by the ITT, is impaired due to surgical and radiotherapeutic intervention, whereas tumoral activity may persist, thus preventing (temporarily) the emergence of GHD.

GHRH and combined GHRH-arginine infusions resulted in significantly higher GH peak responses than the ITT in both patient groups. This observation is consistent with the results obtained by Aimaretti et al. in hypopituitarism due to various etiologies (22). The generally accepted explanation for this difference in the magnitude of the $\mathrm{GH}$ responses is that the GHRH-arginine test combines the

Table 2 Peak GH response during stimulation tests in patients with acromegaly and pituitary tumor control patients.

\begin{tabular}{lll}
\hline & Patients treated for acromegaly & PT control patients \\
\hline Insulin tolerance test $(\mu \mathrm{g} / \mathrm{l})$ & $0.18(0.03-0.92)$ & $0.18(0.01-1.58)$ \\
GHRH test $(\mu \mathrm{g} / \mathrm{l})$ & $0.75(0.15-3.10)$ & $0.80(0.08-2.86)$ \\
GHRH-arginine test $(\mu \mathrm{g} / \mathrm{l})$ & $1.28(0.24-3.80)$ & $1.30(0.11-4.75)$ \\
Arginine test $(\mu \mathrm{g} / \mathrm{l})$ & $0.28(0.02-1.36)$ & $0.19(0.01-1.10)$ \\
\hline
\end{tabular}

Data are shown as median values and data limits are given in parentheses. Statistical comparisons were performed with the Kolmogorov-Smirnov test. Reference values in healthy adults for our laboratory are ITT: $>3 \mu \mathrm{g} / \mathrm{l} ; \mathrm{GHRH}:>3 \mu \mathrm{g} / \mathrm{l}$; arginine test: $>2.9 \mu \mathrm{g} / \mathrm{l} ; \mathrm{GHRH}-\mathrm{arginine}$ test $>8 \mu \mathrm{g} / \mathrm{l}$. 

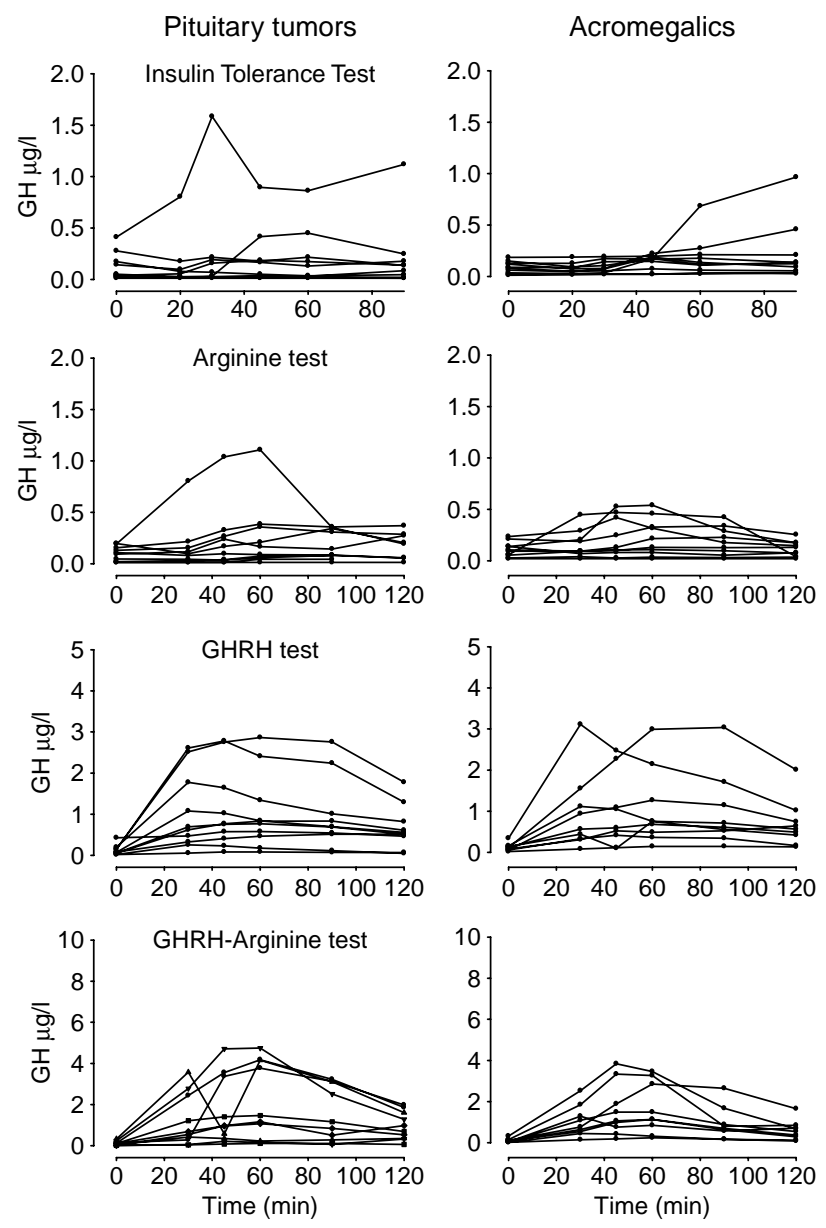

Figure $1 \mathrm{GH}$ response to the ITT, arginine, GHRH and the combined $\mathrm{GHRH}$-arginine tests.

somatostatin-suppressing effect of arginine (23) with direct stimulation of the somatotrop cell by exogenous GHRH (24), whereas the ITT requires endogenous GHRH (25). Our finding that the GHRH test alone resulted in a higher GH response compared to the ITT (in both groups of patients) might point to hypothalamic dysfunction with diminished endogenous drive to the pituitary. These observations are also in line with the study by Murray et al. in which they investigated patients treated for acromegaly with the arginine test and the $\mathrm{GH}$ secretagog hexarelin (26). They reported loss of response to the arginine test in patients treated by radiotherapy, although the response to the $\mathrm{GH}$

Table 3 Cluster analysis of the $24 \mathrm{~h}$ serum GH profiles in patients with acromegaly and pituitary tumor control patients.

\begin{tabular}{lccc}
\hline & Patients treated for acromegaly & Pituitary adenoma control patients & $P$-value \\
\hline Mean 24 $\mathrm{h}$ GH concentration $(\mu \mathrm{g} / \mathrm{l})$ & $0.12(0.07-0.16)$ & $0.20(0.01-0.40)$ & 0.82 \\
Integrated area $(\mu \mathrm{g} / / \mathrm{min})$ & $166(99-230)$ & $300(28-590)$ & 0.82 \\
Number of GH pulses/24 $\mathrm{h}$ & $15(11-19)$ & $11(9-14)$ & 0.37 \\
Mean pulse interval $(\mathrm{min})$ & $92(65-120)$ & $102(75-130)$ & 0.76 \\
Mean pulse amplitude $(\mu \mathrm{g} / \mathrm{l})$ & $0.15(0.10-0.19)$ & $0.33(0.02-0.65)$ & 0.51 \\
Mean pulse area $(\mu \mathrm{g} / / \mathrm{min})$ & $2.20(0.70-3.70)$ & $0.80(0-21.0)$ & $0.16(0.05-0.31)$ \\
Valley mean $(\mu \mathrm{g} / \mathrm{l})$ & $0.10(0.06-0.14)$ & $0.15(0.03-0.27)$ & 0.87 \\
Nadir $(\mu \mathrm{g} / \mathrm{l})$ & $0.09(0.06-0.13)$ & 0.87 \\
\hline
\end{tabular}

Data are given as the mean and $95 \%$ confidence interval. Statistical comparisons were performed with the Kolmogorov-Smirnov test. Reference values for a comparable group of healthy controls are (mean and $95 \% \mathrm{Cl}): 24 \mathrm{~h}$ mean GH concentration $0.60 \mu \mathrm{g} / \mathrm{l}(0.39-0.80)$, integrated area $850 \mu \mathrm{g} / / \mathrm{min}(550-1165)$, number of GH pulses/24 h 9 (8-11), mean pulse interval $155 \mathrm{~min}$ (125-185), mean pulse amplitude $1.40 \mu \mathrm{g} / \mathrm{l}(0.78-2.05)$, mean pulse area $70 \mu \mathrm{g} / / \mathrm{min}$ (35-100), valley mean $0.50 \mu \mathrm{g} / \mathrm{l}(0.1-0.90)$, nadir $0.30 \mu \mathrm{g} / \mathrm{l}(0.10-0.50)$. 

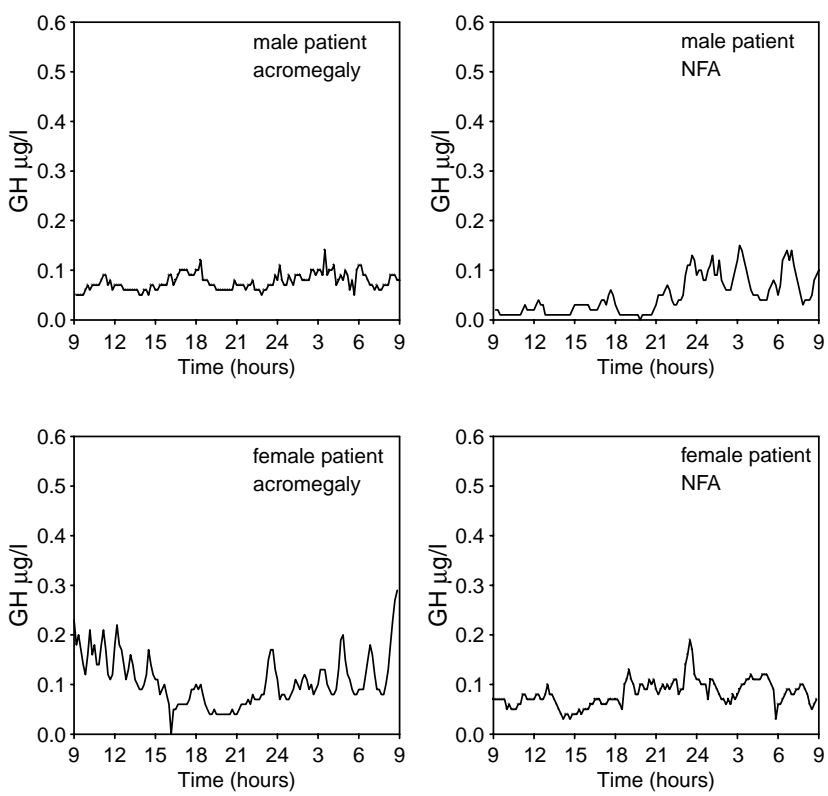

Figure 2 Representative $24 \mathrm{~h}$ GH profiles of two acromegalic patients and two PT control patients.

secretagog was retained in about $50 \%$ of these patients (26).

The diagnosis of GHD in adults is established by provocative testing, since IGF-I concentrations and mean $24 \mathrm{~h} \mathrm{GH}$ concentrations overlap in adults considered GH deficient (i.e. due to extensive pituitary disease) and healthy subjects (27). The combined GHRH-arginine test is also considered to be a reliable test for the detection of GHD (28), provided that appropriate cut-off limits related to BMI are defined (29). However, the GH response to arginine alone is found to be less sensitive to the effects of radiotherapy than the GH response to the ITT (30). In accordance with these inferences, GH responses to arginine and insulin in the present cohorts were identical, although greatly diminished, and comparable to those in patients who received cranial irradiation for non-pituitary diseases (30).

There was a moderately positive correlation between peak GH responses to the ITT and to the combined GHRHarginine test and a strongly positive correlation between the peak response to the ITT and arginine. In addition, the peak response to the ITT and to the combined GHRHarginine test correlated with spontaneous $24 \mathrm{~h} \mathrm{GH}$ secretion. Therefore, from a practical clinical viewpoint, the investigation of $\mathrm{GH}$ reserve capacity in acromegalic patients with cardiovascular disease may be equally well explored with the combined test.

GH secretion in active acromegaly is characterized by increased apparent pulse frequency, burst mass and basal (non-pulsatile) secretion $(15,31,32)$. In contrast, $\mathrm{GH}$ burst mass is decreased profoundly in GHD and total $24 \mathrm{~h}$ secretion is diminished, notwithstanding increased pulse frequency (33). In the present study, treated patients with somatotropinomas and other pituitary adenomas clearly fulfilled the criterion of GHD. A remarkable outcome is that there were no differences in mean $24 \mathrm{~h} \mathrm{GH}$ concentration, number of $\mathrm{GH}$ pulses per $24 \mathrm{~h}$, pulse amplitude or area between the two groups. The spectrum of $\mathrm{GH}$ release extended from complete absence of statistically significant $\mathrm{GH}$ pulses with low basal concentrations, as observed in five patients, to persisting, low-amplitude pulsatility (as illustrated in the figures). It is presently unclear, whether residual $\mathrm{GH}$ output in treated acromegalic patients is derived from normal somatotrope cells or from tumor remnants.

Peacey et al. have described the relationship between $24 \mathrm{~h} \mathrm{GH}$ secretion profiles and IGF-I in cured acromegalic patients (defined as GH levels below $2 \mu \mathrm{g} / \mathrm{l}$ during an oral glucose tolerance test or a GH profile) (34). In that study, elevated mean IGF-I concentrations in acromegalic patients treated by radiotherapy compared with healthy controls were inferred to reflect persisting differences in $24 \mathrm{~h} \mathrm{GH}$ secretion (34). The current data extend insights to two more severely compromised groups in which, irrespective of the underlying disorder, IGF-I concentrations were below -2 s.D. score in all but one subject and uncorrelated with GH secretory parameters.

ApEn, a tool to quantitate the orderliness or regularity of serial GH serum concentrations, did not differ between patients treated for acromegaly and those treated for other pituitary tumors. However, when compared with values reported in normal healthy subjects, ApEn was elevated almost twofold, indicating disorganized $\mathrm{GH}$ secretion (5). Elevated ApEn of GH points to increased feed-forward by GHRH or tumoral cells or decreased feedback via somatostatin, GH and 
IGF-I signaling (35). In active acromegaly, disorganized GH secretion is likely attributed to the tumor per se, akin to that of prolactinomas and ACTH-secreting adenomas $(14,16)$. The anatomical substrate for the disorganized secretion might be defective or autonomous cell-cell interactions in the adenoma $(36,37)$. In hypopituitarism of various etiologies, excluding acromegaly, $\mathrm{GH}$ secretion is also profoundly irregular and not correlated with pituitary irradiation (33). Such secretory alterations might be attributed to a diminished somatostatin and/or GH/IGF-I feedback. Histopathological and controlled feedback studies are required together to elucidate the precise mechanism(s) involved.

We chose to study acromegalic patients with an impaired response to the ITT treated by radiotherapy and to compare these patients with those treated likewise without a previous history of acromegaly. The latter group fulfilled the criteria of GHD. Since no differences in spontaneous and stimulated GH secretion between the two groups were found, it is reasonable to conclude that the acromegalic patients became $\mathrm{GH}$ deficient many years after radiotherapy. Another study has suggested that the prevalence of GHD is high in patients treated by surgery alone (38). Direct comparison of those two groups would be of interest.

In conclusion, acromegalic patients treated by surgery and postoperative radiotherapy with an impaired response to the ITT do not differ, in the long term, in GH secretory characteristics from patients treated similarly for other pituitary tumors with an impaired response to the ITT. The ITT (or the GHRHarginine test) is therefore reliable in establishing the diagnosis of GHD in patients treated for acromegaly by surgery and radiotherapy. Irregular GH secretion, lowamplitude GH pulses, and reduced IGF-I concentrations thus constitute a final common outcome of combined surgery and radiation treatment of pituitary adenomas.

\section{References}

1 Wright AD, Hill DM, Lowy C \& Fraser TR. Mortality in acromegaly. Quarterly Journal of Medicine 197039 1-16.

2 Beauregard C, Truong U, Hardy J \& Serri O. Long-term outcome and mortality after transsphenoidal adenomectomy for acromegaly. Clinical Endocrinology 200358 86-91.

3 Biermasz NR, van Dulken H \& Roelfsema F. Ten-year follow-up results of transsphenoidal microsurgery in acromegaly. Journal of Clinical Endocrinology and Metabolism 200085 4596-4602.

4 Freda PU, Wardlaw SL \& Post KD. Long-term endocrinological follow-up evaluation in 115 patients who underwent transsphenoidal surgery for acromegaly. Journal of Neurosurgery $1998 \mathbf{8 9}$ 353-358.

5 van den Berg G, Pincus SM, Frolich M, Veldhuis JD \& Roelfsema F. Reduced disorderliness of growth hormone release in biochemically inactive acromegaly after pituitary surgery. European Journal of Endocrinology 1998138 164-169.

6 Biermasz NR, van Dulken H \& Roelfsema F. Postoperative radiotherapy in acromegaly is effective in reducing $\mathrm{GH}$ concentration to safe levels. Clinical Endocrinology 200053 321-327.
7 Biermasz NR, van Dulken H \& Roelfsema F. Long-term follow-up results of postoperative radiotherapy in 36 patients with acromegaly. Journal of Clinical Endocrinology and Metabolism 2000 $852476-2482$.

8 Eastman RC, Gorden P, Glatstein E \& Roth J. Radiation therapy of acromegaly. Endocrinology and Metabolism Clinics of North America $199221693-712$.

9 Littley MD, Shalet SM, Beardwell CG, Ahmed SR, Applegate G \& Sutton ML. Hypopituitarism following external radiotherapy for pituitary tumours in adults. Quarterly Journal of Medicine 198970 $145-160$.

10 Consensus guidelines for the diagnosis and treatment of adults with growth hormone deficiency: summary statement of the Growth Hormone Research Society Workshop on Adult Growth Hormone Deficiency. Journal of Clinical Endocrinology and Metabolism 199883 379-381.

11 Veldhuis JD \& Johnson ML. Cluster analysis: a simple, versatile, and robust algorithm for endocrine pulse detection. American Journal of Physiology 1986250 E486-E493.

12 Pincus SM \& Keefe DL. Quantification of hormone pulsatility via an approximate entropy algorithm. American Journal of Physiology 1992262 E741-E754.

13 Veldhuis JD \& Pincus SM. Orderliness of hormone release patterns: a complementary measure to conventional pulsatile and circadian analyses. European Journal of Endocrinology 1998138 358-362.

14 Groote Veldman VR, van den Berg G, Pincus SM, Frolich M, Veldhuis JD \& Roelfsema F. Increased episodic release and disorderliness of prolactin secretion in both micro- and macroprolactinomas. European Journal of Endocrinology $1999140192-$ 200.

15 Hartman ML, Veldhuis JD, Vance ML, Faria AC, Furlanetto RW \& Thorner MO. Somatotropin pulse frequency and basal concentrations are increased in acromegaly and are reduced by successful therapy. Journal of Clinical Endocrinology and Metabolism $1990 \mathbf{7 0}$ 1375-1384.

16 van den Berg G, Pincus SM, Veldhuis JD, Frolich M \& Roelfsema F. Greater disorderliness of ACTH and cortisol release accompanies pituitary-dependent Cushing's disease. European Journal of Endocrinology 1997136 394-400.

17 Hanew K \& Utsumi A. The role of endogenous GHRH in arginine-, insulin-, clonidine- and l-dopa-induced GH release in normal subjects. European Journal of Endocrinology 2002146 197-202.

18 Masuda A, Shibasaki T, Hotta M, Yamauchi N, Ling N, Demura H \& Shizume K. Insulin-induced hypoglycemia, L-dopa and arginine stimulate GH secretion through different mechanisms in man. Regulatory Peptides 199031 53-64.

19 Toogood AA. Endocrine consequences of brain irradiation. Growth Hormone and IGF Research 200414 (Suppl A) S118-S124.

20 Ahmed SR \& Shalet SM. Hypothalamic growth hormone releasing factor deficiency following cranial irradiation. Clinical Endocrinology $198421483-488$.

21 Blacklay A, Grossman A, Ross RJ, Savage MO, Davies PS, Plowman PN, Coy DH \& Besser GM. Cranial irradiation for cerebral and nasopharyngeal tumours in children: evidence for the production of a hypothalamic defect in growth hormone release. Journal of Endocrinology 1986108 25-29.

22 Aimaretti G, Corneli G, Razzore P, Bellone S, Baffoni C, Arvat E, Camanni $\mathrm{F} \&$ Ghigo E. Comparison between insulin-induced hypoglycemia and growth hormone (GH)-releasing hormone+ arginine as provocative tests for the diagnosis of GH deficiency in adults. Journal of Clinical Endocrinology and Metabolism $1998 \mathbf{8 3}$ 1615-1618.

23 Alba-Roth J, Muller OA, Schopohl J \& von Werder K. Arginine stimulates growth hormone secretion by suppressing endogenous somatostatin secretion. Journal of Clinical Endocrinology and Metabolism 198867 1186-1189.

24 Grossman A, Savage MO, Lytras N, Preece MA, Sueiras-Diaz J, Coy DH, Rees LH \& Besser GM. Responses to analogues of growth hormone-releasing hormone in normal subjects, and in growthhormone deficient children and young adults. Clinical Endocrinology 198421 321-330. 
25 Jaffe CA, DeMott-Friberg R \& Barkan AL. Endogenous growth hormone $(\mathrm{GH})$-releasing hormone is required for $\mathrm{GH}$ responses to pharmacological stimuli. Journal of Clinical Investigation $1996 \mathbf{9 7}$ 934-940.

26 Murray RD, Peacey SR, Rahim A, Toogood AA, Thorner MO \& Shalet SM. The diagnosis of growth hormone deficiency (GHD) in successfully treated acromegalic patients. Clinical Endocrinology $20015437-44$.

27 Hoffman DM, O'Sullivan AJ, Baxter RC \& Ho KK. Diagnosis of growth-hormone deficiency in adults. Lancet $1994 \mathbf{3 4 3}$ 1064-1068.

28 Valetto MR, Bellone J, Baffoni C, Savio P, Aimaretti G, Gianotti L, Arvat E, Camanni F \& Ghigo E. Reproducibility of the growth hormone response to stimulation with growth hormone-releasing hormone plus arginine during lifespan. European Journal of Endocrinology 1996135 568-572.

29 Corneli G, Di Somma C, Baldelli R, Rovere S, Gasco V, Croce CG, Grottoli S, Maccario M, Colao A, Lombardi G, Ghigo E, Camanni F \& Aimaretti G. The cut-off limits of the GH response to GH-releasing hormone-arginine test related to body mass index. European Journal of Endocrinology 2005153 257-264.

30 Lissett CA, Saleem S, Rahim A, Brennan BM \& Shalet SM. The impact of irradiation on growth hormone responsiveness to provocative agents is stimulus dependent: results in 161 individuals with radiation damage to the somatotropic axis. Journal of Clinical Endocrinology and Metabolism $2001 \mathbf{8 6}$ 663-668.

31 Barkan AL, Stred SE, Reno K, Markovs M, Hopwood NJ, Kelch RP \& Beitins IZ. Increased growth hormone pulse frequency in acromegaly. Journal of Clinical Endocrinology and Metabolism 1989 69 1225-1233.
32 van den Berg G, Frolich M, Veldhuis JD \& Roelfsema F. Growth hormone secretion in recently operated acromegalic patients. Journal of Clinical Endocrinology and Metabolism $1994 \mathbf{7 9}$ 1706-1715.

33 Roelfsema F, Biermasz NR \& Veldhuis JD. Pulsatile, nyctohemeral and entropic characteristics of $\mathrm{GH}$ secretion in adult $\mathrm{GH}$-deficient patients: selectively decreased pulsatile release and increased secretory disorderliness with preservation of diurnal timing and gender distinctions. Clinical Endocrinology 200256 79-87.

34 Peacey SR, Toogood AA, Veldhuis JD, Thorner MO \& Shalet SM. The relationship between 24-hour growth hormone secretion and insulin-like growth factor I in patients with successfully treated acromegaly: impact of surgery or radiotherapy. Journal of Clinical Endocrinology and Metabolism 200186 259-266.

35 Veldhuis JD, Straume M, Iranmanesh A, Mulligan T, Jaffe C, Barkan A, Johnson ML \& Pincus S. Secretory process regularity monitors neuroendocrine feedback and feedforward signaling strength in humans. American Journal of Physiology 2001280 R721-R729.

36 Fauquier T, Guerineau NC, McKinney RA, Bauer K \& Mollard P. Folliculostellate cell network: a route for long-distance communication in the anterior pituitary. Proceedings of the National Academy of Sciences USA 200198 8891-8896.

37 Mollard P. Functional Cell Networks in the Pituitary Gland; The Endocrine Society's 87th Annual Meeting, San Diego, 2005 S35-S32

38 Conceicao FL, Fisker S, Andersen M, Kaal A, Jorgensen JO, Vaisman M \& Christiansen JS. Evaluation of growth hormone stimulation tests in cured acromegalic patients. Growth Hormone and IGF Research 200313 347-352.

Received 17 December 2005

Accepted 16 March 2006 